\title{
Isolation and Antimicrobial Susceptibility Pattern of Urinary Escherichia Coli in Dhaka Medical College Hospital, Bangladesh
}

\author{
*TA Binte Islam ${ }^{1}$, SM Shamsuzzaman ${ }^{2}$, I Rahman ${ }^{3}$, F Ferdous ${ }^{4}$ \\ ${ }^{1}$ Dr. Tashmin Afroz Binte Islam, Assistant Professor of Microbiology, Tairunnessa Memorial Medical College, Gazipur, Bangladesh \\ ${ }^{2}$ Prof. S M Shamsuzzaman, Professor of Microbiology, Dhaka Medical College, Dhaka, Bangladesh \\ ${ }^{3}$ Dr. Irin Rahman, Assistant Professor of Microbiology, Ashiyan Medical College, Dhaka, Bangladesh \\ ${ }^{4}$ Dr. Faria Ferdous Assistant Professor of Microbiology, Tairunnessa Memorial Medical College, Gazipur, Bangladesh
}

*Corresponding Author

Date of submission: 12 July 2015

Date of acceptance: 16 November 2015

\begin{abstract}
Background: Escherichia coli is the major bacterial pathogen being isolated and reported from urine, globally. For these uropathogens the therapeutic management becomes limited, so knowledge about the antimicrobial resistance pattern of these agents at a specific area may help the doctors to choose correct treatment regimen. The aim of the current study was to detect the common uropathogens from urine and the antimicrobial susceptibility pattern of Escherichia coli in Dhaka Medical College Hospital (DMCH).
\end{abstract}

Methods: Samples were collected over a period of 12 months from July 2011 to June 2012 from the patients of DMCH irrespective of age and sex. Samples were cultured in blood agar and MacConkey agar media and organisms were identified by different biochemical tests such as oxidase test, reaction in MIU and simmon's citrate media and different sugar fermentation tests. Data were analyzed using Microsoft Excel (2007).

Results: From total 300 urine samples, 177 (59\%) Gram-positive and Gram-negative bacteria were isolated. Among them, Esch. coli was the most predominant $112(63.28 \%)$ organism followed by Enterobacter spp. (11.87\%). The prevalence of Esch. coli was significantly higher in females (63.39\%) of younger age group than in males $(36.61 \%)$. Esch. coli was highly sensitive to imipenem (100\%) followed by ceftriaxone $(62.50 \%)$, ceftazidime $(55.36 \%)$ and azitromycin $(35.72 \%)$ respectively. Low sensitivity patterns were found against doxycycline (13.39\%), co-trimoxazole (16.07\%), amoxiclav (21.43\%) and ciprofloxacin $(23.22 \%)$ respectively.

Conclusion: The result of this study provides insight into the high proportion of multidrug resistant Escherichia coli and creates a need to report them routinely in laboratories.

Key Words: Escherichia coli, urine

\section{Introduction}

Antimicrobial resistance among bacterial strains is an emerging problem, worldwide. Urinary tract infections (UTIs) are one of the most common bacterial infections in humans both in the community and the hospital settings ${ }^{1-3}$. Escherichia coli are the pre-dominant pathogen commonly isolated in urine. These uropathogens have also developed resistance to commonly prescribed antimicrobial agents which severely limits the treatment options.

The prevalence of UTIs increases among patients from lower socio-economical group. UTIs including catheter related bacteriuria constitute the most common nosocomial bacterial infection with an average rate of 13.1 cases per 1000 hospital discharges ${ }^{4}$. Due to this high prevalence UTIs warrant careful consideration by the clinicians. More than $90 \%$ of all uncomplicated UTIs are caused by Esch. coli infection ${ }^{5}$. Esch. coli causes a wide range of UTIs, including uncomplicated urethritis or cystitis, symptomatic cystitis, pyelonephritis, acute prostatitis, prostatic abscess, and urosepsis 6 .

An increasing antimicrobial resistance in Esch. coli 
has been reported worldwide which is a crucial problem. The high consumption of often inappropriately prescribed broad spectrum antibiotics combined with overcrowding, multiple pathology and frequent use of invasive devices are the major factors contributing high level of resistance ${ }^{7}$. A continuous rise of resistance to different antimicrobial drugs complicates the treatment strategy of urinary tract infections. The prevalence and antimicrobial susceptibility profile of Esch. coli show considerable topographical differences as well as significant variations in different environments and populations ${ }^{8}$.

The present study has documented the distribution of urinary pathogens and multi drug resistance pattern of Esch. coli isolated from urinary tract infected patients in Dhaka Medical College Hospital.

\section{Materials and Methods}

Study design and population: It was a crosssectional study. Urine samples were collected from the patients who were earlier admitted in inpatient department or visited the outpatient department of Dhaka Medical College Hospital. Clean catch mid stream urine samples were collected in sterile containers. The patients comprised both sexes and all the age groups.

Bacterial isolates: A total of 300 urine samples were collected during July 1, 2011 to June 30, 2012 in the Department of Microbiology, Dhaka Medical College, Bangladesh. Approval was obtained from research review committee (RRC) and ethical review committee (ERC) of Dhaka Medical College according to declaration of Helsinki and national and institutional standards. Written consent was obtained from all participants.

Isolation of gram-negative bacteria: All the samples were inoculated on blood agar and MacConkey agar media and incubated at $37^{\circ} \mathrm{C}$ aerobically for 24 hours. The incubated plates were examined for bacterial growth and the organisms were identified by colony morphology, hemolytic criteria, staining character, pigment production and biochemical tests such as oxidase test, reaction in MIU and simmon's citrate media and different sugar fermentation tests ${ }^{9}$.
Antimicrobial susceptibility testing: Samples which showed significant colony count were taken into consideration and antimicrobial susceptibility pattern was determined by Kirby Bauer diskdiffusion method on Mueller-Hinton agar using commercially available antibiotic discs (Oxiod, Hampshire, UK) according to CLSI guidelines10. The antibiotic disk used in antibiogram for all the Esch. coli were co-trimoxazole $(1.25 / 23.75 \mu \mathrm{g})$, gentamycin $\left(\begin{array}{ll}10 & \mu \mathrm{g}\end{array}\right)$, ciprofloxacin $(5 \mu \mathrm{g})$, doxycycline $(30 \mu \mathrm{g})$, azithromycin $(30 \mu \mathrm{g})$, amoxiclav $(20+10 \mu \mathrm{g})$, ceftriaxone $(30 \mu \mathrm{g})$, ceftazidime $(30 \mu \mathrm{g})$ and imipenem $(10 \mu \mathrm{g})$. Escherichia coli ATCC 25922 was used for quality control.

\section{Data analysis}

Data were analyzed using Microsoft Excel (2007).

\section{Results}

Out of 300 mid stream urine samples 177 (59\%) showed significant growth of bacteria from in patient department \& out patient department (Table I).

Table-I: Rate of isolation of bacteria from urine sample $(n=300)$

\begin{tabular}{lcc}
\hline Isolated bacteria & Frequency & Percentage \\
\hline Significant growth & 177 & 59.00 \\
No growth & 123 & 41.00 \\
Total & 300 & 100.00 \\
\hline
\end{tabular}

Esch. coli was the most predominant (63.28\%) Gram negative urinary pathogens followed by Enterobacter spp. (11.87\%), Acinetobacter baumannii $(5.65 \%)$ and Klebsiella pneumoniae $(3.96 \%)$. Of the Gram positive bacteria, Enterococci $(8.47 \%)$ was the predominant. Other Gram positive isolates were Staphylococcus aureus (1.69\%) and Staphylococcus saprophyticus (1.13\%) (Table II). 
Table-II: Frequencies of microbial isolates from urine $(n=177)$

\begin{tabular}{lrc}
\hline Species of bacteria & Number & Percentage \\
\hline Esch. coli & 112 & 63.28 \\
Enterobacterspp. & 21 & 11.87 \\
$\quad$ Enterobacter aerogenes-19 & & \\
$\quad$ Enterobacter cloacae- 2 & & \\
Enterococci spp. & 15 & 8.47 \\
Acinetobacter baumannii & 10 & 5.65 \\
Klebsiella pneumoniae & 7 & 3.96 \\
Staphylococcus aureus & 3 & 1.69 \\
Pseudomonas aeruginosa & 3 & 1.69 \\
$\quad$ Proteus vulgaris & 2 & 1.13 \\
Citrobacter freundii & 2 & 1.13 \\
Staphyl ococcus saprophyticus & 2 & 1.13 \\
\hline
\end{tabular}

This study found that most $(63.39 \%)$ Esch. coli associated UTI cases were in the age group of 21-40 years followed by $41-60$ years $(24.11 \%)$ with male and female distribution were $36.61 \%$ and $63.39 \%$ respectively (Table III).

Table-III: Age and sex distribution of Esch. coli culture positive cases $(n=112)$

\begin{tabular}{lrrr}
\hline Age group in years & $\begin{array}{r}\text { Male } \\
\mathbf{n}(\%)\end{array}$ & $\begin{array}{r}\text { Female } \\
\mathbf{n}(\%)\end{array}$ & $\begin{array}{r}\text { Total } \\
\mathbf{n}(\%)\end{array}$ \\
\hline 20 & $2(1.78)$ & $8(7.14)$ & $10(8.92)$ \\
$21-40$ & $20(17.86)$ & $51(45.53)$ & $71(63.39)$ \\
$41-60$ & $16(14.29)$ & $11(9.82)$ & $27(24.11)$ \\
$\geq 60$ & $3(2.68)$ & $1(0.90)$ & $4(3.58)$ \\
Total & $\mathbf{4 1 ( 3 6 . 6 1 )}$ & $\mathbf{7 1 ( 6 3 . 3 9 )}$ & $\mathbf{1 1 2}(\mathbf{1 0 0 . 0 0 )}$ \\
\hline
\end{tabular}

Esch. coli had been shown highly sensitive (100\%) to imipenem followed by ceftriaxone $(62.50 \%)$, ceftazidime $(55.36 \%)$ and azitromycin $(35.72 \%)$ respectively. Low sensitivity patterns were shown against doxycycline (13.39\%), co-trimoxazole (16.07\%), amoxiclav (21.43\%) and ciprofloxacin (23.22\%) respectively (Table IV).
Table-IV: Antimicrobial susceptibility pattern of Esch. $\operatorname{coli}(\mathrm{n}=112)$

\begin{tabular}{lcc}
\hline $\begin{array}{c}\text { Antimicrobial } \\
\text { Agents }\end{array}$ & $\begin{array}{c}\text { Sensitive } \\
\mathbf{n}(\%)\end{array}$ & $\begin{array}{c}\text { Resistant } \\
\mathbf{n}(\%)\end{array}$ \\
\hline Imipenem & $112(100.00)$ & $0(0.00)$ \\
Azithromycin & $40(35.72)$ & $72(64.28)$ \\
Ciprofloxacin & $26(23.22)$ & $86(76.78)$ \\
Ceftriaxone & $70(62.50)$ & $42(37.50)$ \\
Gentamycin & $33(29.47)$ & $79(70.53)$ \\
Amoxiclav & $24(21.43)$ & $88(78.57)$ \\
Co- trimoxazole & $18(16.07)$ & $94 \quad(83.93)$ \\
Doxycycline & $15(13.39)$ & $97(86.61)$ \\
Ceftazidime & $62(55.36)$ & $50(44.64)$ \\
\hline
\end{tabular}

\section{Discussion}

Urinary tract infection is one of the most common infectious diseases encountered in the medical practices and only second to respiratory tract infections as a cause of hospital visit11. Esch. coli is the leading cause of both community-acquired and nosocomial UTIs. The commonly prevailing factors like promiscuity, peer group influence, pregnancy, low socio-economic status]which are common among young men and women living in urban centers play a vital role in causing UTI12,13. It has been usually observed that UTI most commonly occurs in females and up to one-third of all women experience UTI at some point during their lifetimes ${ }^{14}$.

In this study, urine samples from 300 subjects were cultured of which 177 (59\%) showed significant growth. This correlates with the findings of other studies ${ }^{15,16}$. Among the total 177 isolates, Esch. coli was the most predominant pathogen $(63.28 \%)$ followed by Enterobacter spp. (11.87\%), Acinetobacter baumannii (5.65\%) and Klebsiella pneumoniae $(3.96 \%)$. Of the Gram positive bacteria, Enterococci $(8.47 \%)$ was the predominant followed by Staphylococcus aureus (1.69\%) and Staphylococcus saprophyticus (1.13\%) The predominance of Esch. coli associated UTI correlates with the findings of other studies ${ }^{16-18}$. The reason of the highest rate of isolation of Esch. coli is that they are the normal fecal flora and uropathogenic strains of Esch. coli have an adherence factor called fimbriae, or pili, which mediate the attachment to uroepithelial cells ${ }^{19}$. 
In this study, UTI was found more in females $(63.39 \%)$ than in males $(36.61 \%)$. Maximum numbers of patients were found in age group 21-40 years. The findings are in agreement with the reports of other authors who found that $66 \%-71.1 \%$ cases were females and $28.9 \%-34 \%$ were males ${ }^{20,21}$. The high prevalence of infection in females is usually related to anatomical and pathogenic factors, eg, the short length of the urethra and hence lesser distance for bacteria to ascend up the tract, hormonal changes and short distance of urethra to anus ${ }^{22}$.

The antibiogram of isolated Esch. coli of the present study reveals that maximum resistance was found against doxycycline $(86.61 \%)$ followed by cotrimoxazole (83.93\%), amoxiclav (78.57\%), ciprofloxacin $(76.78 \%)$ respectively. $62.50 \%$ Esch. coli were sensitive to ceftriaxone. Imipenem was found to be $100 \%$ sensitive towards Esch. coli which correlates with the studies done by other authors ${ }^{16,23}$.

These increasing resistance patterns against commonly used antibiotics may be due to the fact that the antibiotic is being overprescribed, handed out to patients who have no bacterial infections ${ }^{24}$. The inappropriate usage of wide spectrum antibiotics, insufficient hygiene, immunosuppression, and a prolonged stay in the hospital are some other major etiological factors that elevate the chances of MDR infections $^{25}$. The rapid emergence of antibiotic resistant strains such as ESBL, MBL producing strains alert us that we should cautious with indiscriminate use of antibiotics as well as antibiotics should be prescribed with proper dose and duration after culture and sensitivity reports.

\section{Conclusion}

The data presented in this study may help the clinicians in the rational choice of antibiotic therapy and to prevent misuse, or over use of antibiotics. The disc diffusion method which was used to assess sensitivity and resistance may also be correlated clinically but further investigations for assessing the minimum inhibitory concentrations method will be needed to obtain more reliable and better results.

\section{Acknowledgement}

The authors gratefully acknowledge the technical support provided by Department of Microbiology, Dhaka Medical College.

Conflict Of Interest : Nothing to declare.

\section{References}

1. Ullah F, Malik SA, Ahmed J: Antibiotic susceptibility pattern and ESBL prevalence in nosocomial Escherichia coli from urinary tract infections in Pakistan. Afr $\mathbf{J}$ Biotechnol. 2009; 8: 3921-3926.

2. Cox CE: Nosocomial urinary tract infections. Urol. 1988; 32: 210-215.

3. Gonzalez CM, Schaeffer AJ: Treatment of urinary tract infection: what's old, what's new, and what works. World J Urol. 1999; 17: 372-382.

4. Hooton TM, Bradley SF, Cardenas DD, Colgan R, Geerlings ES, et al. Diagnosis, prevention, and treatment of catheter associated urinary tract infection in adults: 2009 International Clinical Practice Guidelines from the Infectious Diseases Society of America. Clin Infect Dis. 2010; 50: 625-663.

5. Foxman B, Manning SD, Tallman P, Bauer R, Zhang L, Koopman JS, et al. Uropathogenic Escherichia coli are more likely than commensal E. coli to be shared between heterosexual sex partners. Am J Epidemiol. 2002; 156: 1133-1140.

6. Little P, Merriman R, Turner S, Rumsby K, Warner G, $\mathrm{L}$ owes JA, et al. Presentation, pattern, and natural course of severe symptoms, and role of antibiotics and antibiotic resistance among patients presenting with suspected uncomplicated urinary tract infection in primary care: observational study. BMJ. 2010; 340: 5633.

7. Kurin CM. Detection prevention management of urinary tract infections. 5th edition. Baltimore: Williams and Wilkins; 1997. p: 128-164.

8. Erb A, Stürmer T, Marre R, Brenner H. Prevalence of antibiotic resistance in Escherichia coli: overview of geographical, temporal, and methodological variations. EJCMID. 2007; 26: 83-90.

9. Baron EJ, Peterson LR, Finegold SM. Enterobacteriaceae. In: Forbes BA, Sahm DF, Weissfeld AS (eds). Bailey and Scott's diagnostic microbiology. 9th ed. St Louis: Mosby; 1994, p. 374-379.

10. Performance standards for antimicrobial susceptibility testing. Tenth informational supplement. National Committee for Clinical Laboratory Standards (NCCLS), 2000: M100-S10 (M2): 14-21. 
11. Liperky BA. Urinary tract infection in men: epidemiology ,pathophysiology, diagnosis \& treatment. Ann Intern Med. 1989; 111: 138-50.

12. DoHS Annual Report of 2055/56, Department of Health Service HMG Nepal, 2000.

13. Kolawale AS, Kolawale OM, Kandaki-Olukemi YT, Babatunde SK, Durowade KA, Kplawale CF. Prevalence of urinary tract infections among patients attending Dalhatu Araf Specialist Hospital, Lafia, Nasarawa State, Nigeria. Int J Med Medical Sci. 2009; 1: 163-167.

14. Palac DM. Urinary tract infection in women. A physician's perspective, 1986. p. 17-25.

15. Kalsi J, Arya M, Wilson P, Mundy A. Hospital-acquired urinary tract infection. Int J Clin Pract. 2003; 57: 388-391.

16. Jhora ST, Paul S, Begum BA, Chowdhury AQ. Antibiogram of urinary Escherichia coli isolated in Sir Salimullah Medical College Mitford Hospital, Dhaka. Bangladesh J Med Micribiol. 2011; 5: 23-26.

17. Ahmed AA, K hatun M, Alam MJ. Antibacterial susceptibility of common aerobic bacteria of hospitalized patients. Mymensingh Medical J. 1995; 4: 256-260.

18. Das RN, Chandrashekhar TS, Joshi HS, Gurung M, Shrestha N, Siivananda PG. Frequency \& susceptibility profile of pathogens causing urinary tract infection in a tertiary care hospital in Western Nepal. Singapore Med J. 2006; 47: 281-284.
19. Johnson JR. Virulence factors in Escherichia coli urinary tract infection. Clin Microbiol Rev. 1991; 4: 80-128.

20. Parvin US, Hossain MA, Musa AK, Mahamud C, Islam MT, Haque N, et al. Pattern of aerobic bacteria with antimicrobial susceptibility causing community acquired urinary tract infection. Mymensingh Medical J. 2009; 18: 148-153.

21. Ahmed MU, Khairuzzaman M, Begum A, Ahmed I. Isolation and Antimicrobial Susceptibility Pattern of Escherichia coli Causing Urinary Tract Infection in Enam Medical College Hospital. J Enam Med Col. 2011; 1: 60-62.

22. Inabo HI, Obanibi HB. Antimicrobial susceptibility of some urinary tract clinical isolates to commonly used antibiotics. Afr J Biotechnol. 2006; 5: 487-489.

23. Shahnaz S. Murshed M. Rahman T. Urinary pathogens \& its culture sensitivity pattern in Holy Family Red Crecent Medical CollegeHospital, Dhaka,B angladesh. Bangladesh Private Practitioners' Journal. 2005; 11: 19-22

24. Barnett BJ, Stephens DS. Urinary tract infection: an overview. Am J Med Sci. 1997; 314: 245-249.

25. Manjunath GN, Prakash R, Annam V, Shetty K. "The changing trends in the spectrum of the antimicrobial drug resistance pattern of uropathogens which were isolated from hospitals and community patients with urinary tract infections in Tumkur and Bangalore," IJBMR. 2011; 2: 504-550. 